\title{
The Moderating Role of Empathy in the Association Between Parental Support and Adolescent Aggressive and Delinquent Behavior
}

\author{
Jolien Van der Graaff*, Susan Branje, Minet De Wied, and Wim Meeus \\ Research Centre Adolescent Development, Utrecht University, Utrecht, The Netherlands
}

\begin{abstract}
The present two-wave longitudinal study addressed the role of affective empathy and parental support in aggressive and delinquent behavior in a sample of 323 adolescents (158 boys, 165 girls). Self-report questionnaires were used to assess affective empathy, perceived support from parents, delinquency, and aggression. Guided by theories on children's differential susceptibility to socialization, we expected adolescents with different levels of empathy to vary in their responsiveness to parental support. In agreement with our hypothesis, empathy moderated the relation of perceived parental support with aggressive and delinquent behavior. Controlling for the effect of gender and for the stability of aggression and delinquency, higher perceived parental support was predictive of lower levels of aggression at age 15, but only for adolescents high in empathy. Remarkably, adolescents low in empathy not only appeared to benefit less from parental support, but even showed more aggression and delinquency at age 15 when they perceived their parents to be more supportive at age 14. Aggr. Behav. 38:368-377, 2012.

(1) 2012 Wiley Periodicals, Inc.
\end{abstract}

Keywords: empathy; parental support; aggression; delinquency; adolescence

\section{INTRODUCTION}

The prevalence of aggressive and delinquent behavior among adolescents is cause of great concern. In 2010 , over $30 \%$ of the Dutch adolescents reported having been involved in acts such as theft, vandalism, and aggression in the past year [Van der Laan and Blom, 2011]. A better understanding of factors that may prevent adolescents from developing these kinds of behavior is, therefore, of great importance. Empathy is believed to be an important factor helping adolescents to refrain from aggressive and delinquent behavior [e.g., Davis, 1996; Miller and Eisenberg, 1988]. Parental support has also been found to be beneficial for adolescents' psychological adjustment, and social behavior [e.g., Helsen et al., 2000; Branje et al., 2008]. However, there is little information on the combined effects of empathy and parental support on the development of aggressive and delinquent behavior. Children and adolescents who show little empathy may be less responsive to the emotional expressions of their parents and may therefore be less affected by parental socialization efforts [Blair, 2003]. Thus, adolescents' empathy may moderate the association between parental support and aggressive and delinquent behavior. The aim of the present study is to examine the effects of empathy and parental support, and their interaction, on aggression and delinquency in a community sample of adolescents.

\section{Empathy and Aggressive and Delinquent Behavior}

Empathy is generally defined as the ability to understand and to share another's emotional state, and includes both a cognitive and an affective component. Cognitive empathy refers to the ability to understand another's internal state, whereas affective empathy refers to an experience of emotions consistent with those of the observed person [Cohen and Strayer, 1996; Hoffman, 2001]. Affective empathy may engender sympathy or empathic concern for another [Eisenberg, 2000; Hoffman, 2001]. Furthermore, dispositional empathy or the general

\footnotetext{
*Correspondence to: Jolien van der Graaff, Research Centre Adolescent Development, Utrecht University, P.O. Box 80140, 3508 TC Utrecht, The Netherlands. E-mail: j.vandergraaff@uu.nl

Received 29 August 2011; Accepted 14 April 2012

Published online 2 July 2012 in Wiley Online Library (wileyonlinelibrary.com). DOI: 10.1002/ab.21435
} 
ability to show empathy can be distinguished from situational empathy or the transient affective reaction elicited in concrete situations. Although mean levels of dispositional empathy tend to increase during adolescence, rank-order stability is substantial [Davis and Franzoi, 1991]. The current study will look at dispositional empathic concern.

Especially the affective component of empathy is assumed to play a pivotal role in the inhibition of aggressive and delinquent acts [e.g., Shechtman, 2002; Jolliffe and Farrington, 2011]. The observation of the victim's expressions of fear or sadness should lead to a sharing of these negative emotions in the aggressor, resulting in feelings of empathic concern. This, in turn, may motivate the aggressor to increase the victim's well-being by stopping the harmful behavior [Davis, 1996; Feshbach and Feshbach, 2009]. Individuals high in empathy are more responsive to others' emotional expressions and therefore are expected to be more likely to inhibit harmful behavior than individuals low in empathy.

Support for the negative relation between affective empathy and aggressive behavior was found in several cross-sectional studies in adolescent samples. For instance, affective empathy appeared to be negatively linked to relational aggression for boys and girls aged 13-16 [Endresen and Olweus, 2001] and for boys aged 13-17 [Jolliffe and Farrington, 2011]. Higher affective empathy was also found to be associated with lower verbal, physical, and indirect aggression in early adolescents [Kaukiainen et al., 1999]. In some studies the negative association between affective empathy and aggression was only found for male adolescents [e.g., Loudin et al., 2003; Caravita et al., 2009]. Few longitudinal studies investigated the association between empathy and aggression in adolescence. Lower affective empathy at age 13 predicted a persistent trajectory of aggression and vandalism from age 11 to 17 among boys [Carrasco et al., 2006]. In another longitudinal study, higher empathic concern at age 11 predicted lower overt and relational aggression 1 year later [Batanova and Loukas, 2011]. Thus, both crosssectional studies and the few available longitudinal studies show that higher empathy is related to lower levels of aggression in adolescence concurrently and over time.

For the relation between empathy and delinquency, the results of previous studies are less consistent. For instance, Robinson et al. [2007] found a group of adolescent incarcerated offenders not to have lower scores on a self-reported empathy scale than a control group, although the offenders did show less emotional empathy in reaction to videotaped stimulus material than the control group. However, in a study among students with a mean age of 20 years, selfreported empathic concern was found to be significantly negatively related to delinquency [Schaffer et al., 2009]. Furthermore, a meta-analysis across 14 studies showed emotional empathy to be negatively related to offending, although the effect size was small [Jolliffe and Farrington, 2004]. Longitudinal studies on the relation between emotional empathy and delinquency in adolescence are scarce. Higher empathy was significantly associated with lower delinquency 2 years later in a sample of adolescents aged 14-19 at the first measurement [Bandura et al., 2003]. In a study among boys from low-income families, lower empathy at age 12 predicted higher moral disengagement at age 15, which in turn predicted higher levels of delinquency at age 17 [Hyde et al., 2010]. Thus, the results of several studies and a meta-analysis show affective empathy to be negatively related to delinquency in adolescence.

\section{Parental Support and Aggressive and Delinquent Behavior}

Parental support is believed to be an important factor in preventing adolescents from developing aggressive and delinquent behavior [see Branje et al., 2008]. Adolescents who perceive their parents as available for support when needed and who feel encouraged by their parents are less likely to show aggressive or delinquent behavior than adolescents who experience the relationship with their parents to be less supportive. In previous research, parental support was found to be negatively related to both aggression [e.g., Arim et al., 2011] and delinquency [e.g., Barnes et al., 2006].

Negative relations between perceived parental support and aggressive behavior were found in several cross-sectional studies [e.g., Carlo et al., 1999; Estévez et al., 2006] and also in few longitudinal studies. For instance, perceptions of parental nurturance at age 10 predicted lower levels of indirect and direct aggression at age 12 for girls, whereas parental nurturance at age 12 was predictive of less aggressive behavior at age 14 for boys [Arim et al., 2011]. Furthermore, a study on the impact of corporal punishment and parental support showed that not persistent corporal punishment per se, but the lack of parental support and involvement that often accompanies a harsh parenting style, increased the adolescent's risk for developing delinquent and aggressive behavior [Simons et al., 1994]. Thus, parental support is negatively related to aggressive behavior during adolescence both concurrently and over time.

Parental support was also found to be negatively related to delinquency in several cross-sectional studies [e.g., Windle, 1992; Deković et al., 2003]. A 
meta-analysis [Hoeve et al., 2009] showed parental support to be negatively related to delinquent behavior across 72 studies and a total of 49.960 (mainly adolescent) subjects. Furthermore, in a longitudinal six-wave study, adolescents who reported high family support showed lower initial delinquency levels and showed less increase of delinquency over time [Barnes et al., 2006]. Meeus et al. [unpublished work] found similar effects in a 6-year longitudinal study for single adolescents aged 12 till 20 years. Thus, a lack of parental support appears to be a risk factor in the development of delinquent behavior during adolescence.

\section{The Moderating role of Empathy}

Although rearing experiences, such as parental support, are believed to have beneficial effects for psychological adjustment, a growing number of studies shows that the degree to which children are responsive to parental socialization efforts may be affected by certain child characteristics [e.g., Kochanska, 1997; Caspi and Moffitt, 2006; Klein Velderman et al., 2006]. Belsky's [1997, 2005] theory on differential susceptibility suggests that the particular characteristics that make children more vulnerable to environmental adversity also make them more likely to benefit from supportive contextual influences. Although most of the empirical studies on differential susceptibility have focused on the effects of early rearing influences, there is some evidence suggesting that beyond early childhood, environmental influences may also differentially affect children and adolescents with different characteristics [Branje et al., 2010; Essex et al., 2011]. Thus, although parental support seems to be negatively related to the development of delinquent and aggressive behavior during adolescence, for some adolescents this association may be stronger than for others.

An individual characteristic that may make adolescents differentially susceptible to parental support is empathic concern. Individuals low in empathic concern for others may care less about having warm and affective relationships and may therefore be less affected by socialization efforts than individuals who show more empathic concern [Lahey et al., 1999]. Furthermore, adolescents low in empathy are less sensitive to the communicatory signals that are given by emotional expressions of their parents and may have difficulties in interpreting these signals [Blair, 2003]. This may result in a lower susceptibility to the effects of parental support and approval.

Evidence from cross-sectional studies in clinical samples showed that for children who lack empa- thy, parenting was unrelated to externalizing behavior, suggesting that a lack of empathy inhibits the effects of parenting [e.g., Wootton et al., 1997; Oxford et al., 2003; Edens et al., 2008]. However, the children in these clinical samples not only displayed little empathy but were also characterized as unemotional and lacking feelings of guilt. Few studies have examined the combined effects of empathy and parental support in community samples. Only one study [De Kemp et al., 2007] investigated the moderating role of empathy in the relation between parental support and aggressive and delinquent behavior in adolescence. The association between parental support and aggressive and delinquent behavior appeared not to be moderated by empathy in this study. However, this could be due to the design of the study in that empathy was measured at the second time point. Thus, although results of studies in clinical samples suggest that the effect of parenting on aggressive and delinquent behavior may differ for children varying in empathy, there is a lack of studies in community samples on the moderating role of empathy in adolescence.

\section{Gender Differences}

Gender differences in empathy, parental support, and aggressive and delinquent behavior are wellestablished in the literature. Previous studies consistently found girls to score higher on empathy than boys, especially when empathy is self-reported [e.g., Eisenberg and Lennon, 1983; Davis and Franzoi, 1991; Olweus and Endresen, 1998]. For aggressive and delinquent behavior, boys generally show higher levels than girls [e.g., Moffitt and Caspi, 2001; Card et al., 2008]. Furthermore, previous studies found girls to report more parental support than boys [Helsen et al., 2000]. In the current study, gender differences in empathy, aggression, delinquency, and parental support will be examined, and gender will be included as a covariate in further analyses to control for gender differences.

\section{Research Aims and Hypotheses}

The aim of the present study is to investigate the effects of emotional empathy, parental support, and their interaction on adolescents' aggressive and delinquent behavior. We expect adolescents who report lower affective empathy to show more aggressive and delinquent behavior than adolescents who report higher levels of affective empathy. Further, we hypothesize perceived parental support to be negatively related to aggression and delinquency. Moreover, we expect that parental support will interact with empathy in the prediction of aggressive and delinquent 
behavior. Highly empathic adolescents are expected to be more susceptible to the beneficial effects of parental support as well as the adverse effects of a lack of support, than adolescents with low empathy. Therefore, parental support is predicted to be more strongly related to changes in aggressive and delinquent behavior in highly empathic adolescents than in adolescents with low empathy.

\section{METHOD}

\section{Participants}

The current sample of 323 adolescents (158 boys, 165 girls) was drawn from the ongoing CONAMORE longitudinal study [CONflicts And Management Of RElationships; Meeus et al., unpublished work] in which 938 adolescents annually completed a battery of questionnaires at school from early adolescence on. The 323 adolescents of the current study not only participated in the school assessments, but also in home visits in which the adolescent and both parents filled out questionnaires. This so-called 'family sample' was selected from the total sample as follows: first, we asked all adolescents who came from two-parent Dutch families $(n=656)$ if they were willing to participate with both parents in additional home visits. Second, because of the restricted financial budget for the study, out of the 401 families who accepted this invitation, 323 were randomly selected to participate in the family sample. The current study uses data of two measurement waves with a 1-year interval from the family sample. Mean age of the adolescents at Time 1 of the current study was $14.30(\mathrm{SD}=.53)$, and $98.4 \%$ of the adolescents lived with both parents. Different levels of education were represented, with approximately $49 \%$ at schools preparing for university, $34 \%$ preparing for higher education, and $17 \%$ for lowerlevel jobs. The main ethnic identity of all adolescents was Dutch [for a full description of the sample and procedure see Van Doorn et al., 2011].

$t$-tests were performed to examine whether there were differences between adolescents of two-parent Dutch families who participated in the family sample $(n=323)$ and those who participated in the school assessments only $(n=333)$. There were no differences in delinquency $(P=.10)$, aggression $(P=.54)$, and perceived parental support $(P=.09)$ between the two groups. Differences in adolescent empathy could not be tested, because only adolescents of the family sample completed this questionnaire.

\section{Procedure}

Adolescents participating in this study came from various high schools located in the province of
Utrecht, The Netherlands. Both adolescents and their parents received written information before the start of the study, and were required to provide informed consent. Interviewers visited the schools and asked participants to gather in classrooms to fill out a questionnaire. During annual home visits, adolescents filled out an additional questionnaire. Results were processed anonymously. Each wave, families received $€ 27$ for participation and adolescents received an additional amount of $€ 10$ for participating at school.

\section{Measures}

Affective empathy. A Dutch version of Bryant's [1982] Index of Empathy for Children and Adolescents (IECA) was filled out by the adolescents during the home visit at Time 1 . This 22 -item questionnaire assesses dispositional affective empathy. Adolescents were asked to indicate how strongly they agreed or disagreed with the items on a 9-point scale $(-4=$ strongly disagree to +4 strongly agree). A study on the structure of the IECA [De Wied et al., 2007] showed that the IECA consisted of two factors, with the items of the first factor reflecting responsiveness to another person's sadness, and the items of the second factor reflecting attitudes rather than feelings. For the current study, mean scores were calculated from the seven items of the IECA in which responsiveness to another person's sadness is measured. This subscale showed good construct validity and the items are relevant to affective empathy [De Wied et al., 2007]. Sample items are "seeing a boy/girl crying makes me feel like crying" and "it makes me sad to see a boy/girl who can't find anyone to play with". Cronbach's alpha of the scale Empathic Sadness was .82 .

Parental support. The amount of perceived support from mothers and from fathers was measured at Time 1, using the support subscale of the short version of the Network of Relationships Inventory [NRI; Furman and Buhrmester, 1985, 1992]. The support subscale consists of 12 items tapping several relationship qualities like affection, companionship, and admiration (e.g., "does your mother like or approve of the things you do?" or "how much does your father really care about you"). Adolescents filled out the questionnaire for the perceived support from mothers and from fathers separately. Items are rated on a 5-point Likert scale (ranging from $1=$ a little or not at all to $5=$ more is not possible). Previous studies provided support for the reliability and validity of the NRI [Furman and Buhrmester, 1985, 1992]. In the current sample Cronbach's alpha was .89 for perceived support from mothers and .90 for perceived 
support from fathers. The scores of perceived support from mothers and from fathers were highly correlated $(r=.73, P<.001)$, and therefore were averaged to compose one score for perceived parental support.

Aggression. The Direct and Indirect Aggression Scale [Bjorkqvist et al., 1992] was used to measure aggression at Time 1 and Time 2. In the current study, the 17 items of two subscales were used: the subscale direct aggression (e.g., "I kick or strike the other one" or "I call the other one names") and indirect aggression (e.g., "I spread vicious rumors as revenge" or "I tell others not to associate with that person"). Both subscales have good reliability and construct validity [Björkvist et al., 1992]. Adolescents indicated on a 4point Likert scale ranging from 'never' to 'four times or more often', whether they show certain behaviors when they are angry at someone in the classroom. A total aggression score was computed by averaging the scores of the 17 items of direct and indirect aggression Cronbach's alpha of the total aggression scale was .88 at Time 1 and .89 at Time 2. A logarithmical transformation was used on the scores on aggression to reduce skewness.

Delinquency. At Time 1 and Time 2, information about delinquency of the participants was derived from a 16-item questionnaire from Baerveldt et al. [2003], designed to measure minor offences. Adolescents were asked to indicate on a 4-point scale ranging from never to four times or more how often they had shown certain forms of delinquent behavior (e.g., 'stolen a bike, 'deliberately broken something at the street') during the last 12 months. Results of the study of Baerveldt and colleagues [2003] provide support for the internal consistency and validity of the measure. Cronbach's alpha in the current sample was .83 at Time 1 and .82 at Time 2 . The scores on delin- quency were logarithmically transformed to reduce skewness.

\section{RESULTS}

Prior to testing study hypotheses, gender differences in all measures were assessed in preliminary analyses (see Table I). Girls scored significantly higher on empathy than boys, $t(321)=-12.37, P<.001$. There were no gender differences in perceived parental support $(p=.54)$. Boys reported higher levels of aggressive behavior than girls, $F(1,321)=26.70, P<$ .001 , and boys also reported higher levels of delinquent behavior than girls, $F(1,321)=21.48, P<$ .001 . There was no significant difference between age 14 and age 15 mean levels of aggressive behavior $(P=.08)$ and delinquent behavior $(P=.29)$. Table II shows the bivariate correlations for all study variables. As expected, adolescents who reported higher empathy scored lower on aggression and on delinquency at both age 14 and 15 than adolescents who reported lower empathy. Higher perceived parental support was associated with lower aggression at age 14 (but not age 15) and with lower delinquency at both age 14 and 15.

Two hierarchical linear regression analyses were performed to test the main effects of empathy and perceived parental support at age 14 in the prediction of aggression and delinquency at age 15 . Interactions between empathy and parental support were entered to the regressions to test the hypothesis that empathy would moderate the relationships between parental support and aggression and between parental support and delinquency. The scores on empathy and parental support were centered before creating the interaction terms. Gender was recoded into a dummy variable $(0=$ female, $1=$ male $)$. In each regression analysis, the predictors were entered in three hierarchical

TABLE I. Mean Scores for Boys and Girls on Empathy, Parental Support, Aggression (Log Transformed), and Delinquency (Log Transformed)

\begin{tabular}{|c|c|c|c|c|c|c|c|}
\hline & & 23) & & & & & Boys vs. girls \\
\hline & & & & & & & $t$ \\
\hline & & & & & & & \\
\hline Age 14 & .22 & $(1.68)$ & -.76 & (1.44) & 1.15 & $(1.33)$ & $-12.37^{* * *}$ \\
\hline Parental s & & & & & & & \\
\hline Age 14 & 3.58 & $(.58)$ & 3.52 & $(.59)$ & 3.56 & $(.57)$ & .61 \\
\hline Aggressio & & & & & & & \\
\hline Age 14 & .88 & $(.14)$ & .92 & (.14) & .85 & (.14) & $4.07^{* * *}$ \\
\hline Age 15 & .87 & (.14) & .91 & (.14) & .83 & (.12) & $5.20^{* * *}$ \\
\hline Delinquen & & & & & & & \\
\hline Age 14 & .75 & $(.10)$ & .77 & $(.11)$ & .72 & $(.08)$ & $4.89^{* * *}$ \\
\hline Age 15 & .75 & (.10) & .77 & $(.12)$ & .73 & (.09) & $3.65^{* * *}$ \\
\hline
\end{tabular}

Note. ${ }^{* * *} P<.001$. 
TABLE II. Intercorrelations Between Affective Empathy (Age 14), Parental Support (Age 14), Aggression (Log Transformed, Age 14 and 15), and Delinquency (Log Transformed, Age 14 and 15)

\begin{tabular}{|c|c|c|c|c|c|}
\hline & 1. & 2. & 3. & 4. & 5. \\
\hline $\begin{array}{l}\text { 1. Affective } \\
\text { empathy } \\
\text { (age 14) }\end{array}$ & - & & & & \\
\hline $\begin{array}{l}\text { 2. Perceived } \\
\text { parental } \\
\text { support } \\
\text { (age 14) }\end{array}$ & $.22^{* * *}$ & - & & & \\
\hline $\begin{array}{l}\text { 3. Aggressive } \\
\text { behavior } \\
\text { (age 14) }\end{array}$ & $-.14^{*}$ & $-.18^{* *}$ & - & & \\
\hline $\begin{array}{l}\text { 4. Delinquency } \\
\text { (age 14) }\end{array}$ & $-.25^{* * *}$ & $-.30^{* * *}$ & $.37^{* * *}$ & - & \\
\hline $\begin{array}{l}\text { 5. Aggressive } \\
\text { behavior } \\
\text { (age 15) }\end{array}$ & $-.16^{* *}$ & -.11 & $.63^{* * *}$ & $.37^{* * *}$ & - \\
\hline $\begin{array}{l}\text { 6. Delinquency } \\
\text { (age 15) }\end{array}$ & $-.20^{* * *}$ & $-.19^{* * *}$ & $.33^{* * *}$ & $.72^{* * *}$ & $.40^{* * * *}$ \\
\hline
\end{tabular}

steps: (i) gender and aggression or delinquency at age 14, (ii) parental support and empathy at age 14, (iii) the interaction of empathy and parental support. In Table III, standardized beta coefficients, $R$-squares and changes in $R$-squares are reported for each step of the two hierarchical regressions. Significant interactions were examined applying the Johnson-Neyman technique with use of the computational tool provided by Hayes and Matthes [2009] that identifies for which regions in the range of the moderator variable, effects of the focal predictor on the outcome variable are statistically significant [Bauer and Curran, 2005; Hayes and Matthes, 2009].
The first hierarchical regression was conducted on aggression at age 15 with empathy, perceived parental support, and the interaction of empathy and parental support as predictors. The results from the second step of the model show that, after controlling for aggression at age 14, empathy and perceived parental support at age 14 could not predict aggression at age 15. However, in the third step, the interaction of parental support contributed significantly to the prediction of aggression (see Table III). Thus, the association between parental support and aggression differs for adolescents varying in level of empathy. Using the Johnson-Neyman technique [see Hayes and Matthes, 2009], the interaction was probed, revealing that for adolescents with empathy scores higher than 1.57 standard deviations above mean, the effect of perceived parental support on aggression was significantly negative $(P<.05$, significant coefficients ranging from $b=-.04$ to $b=-.05$ ). Remarkably, for adolescents with empathy scores lower than 1.84 standard deviations below mean, higher perceived parental support was associated with higher aggression scores $(P<.05$, ranging from $b=.04$ to $b=.05)$. Figure 1 visualizes the interactive effect by showing simple slopes for adolescents with high and low empathy scores (1 SD above and below mean).

The second hierarchical regression was conducted on delinquency at 15 years with empathy and perceived parental support, and the interaction of empathy and parental support as predictors. Again, results of the second step of the analysis showed that perceived parental support and adolescent empathy at age 14 did not predict delinquency at age 15 , but the interaction of parental support and empathy in the third step did contribute significantly and negatively

TABLE III. Longitudinal Hierarchical Regression Analyses Predicting Aggression (Log Transformed) and Delinquency (Log Transformed) at Age 15 as a Function of Parental Support and Empathy, and the Interaction of Parental Support and Empathy

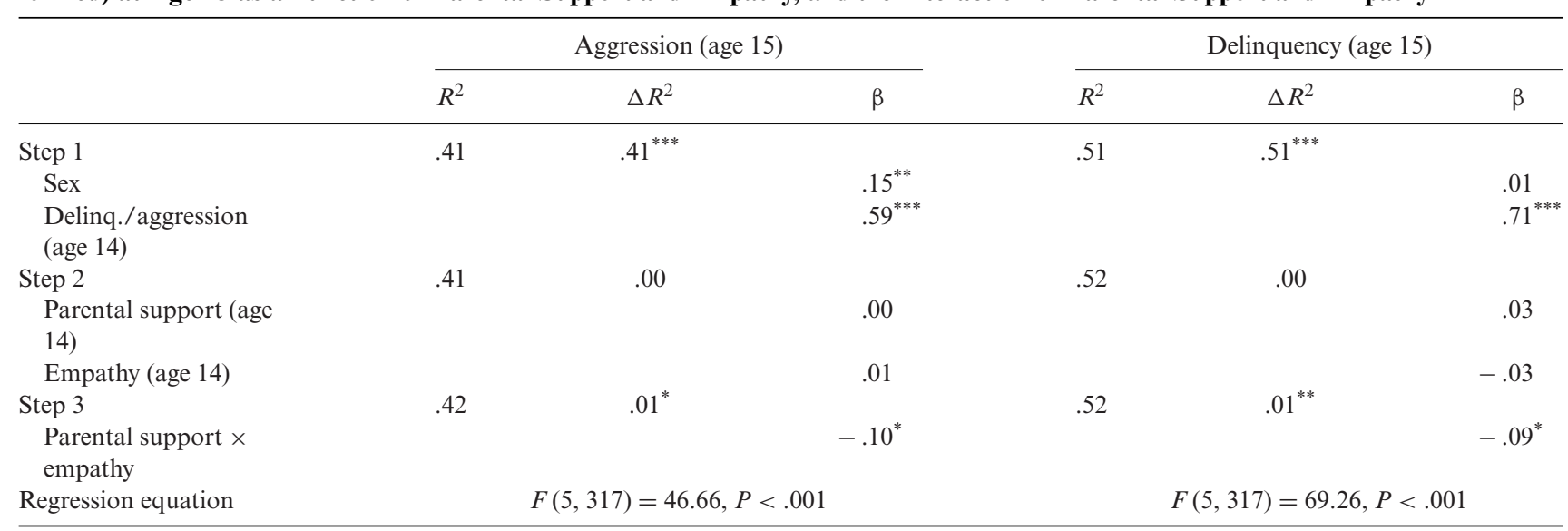

Note. ${ }^{*} P<.05 ;{ }^{* *} P<.01 ;{ }^{* * *} P<.001$. 


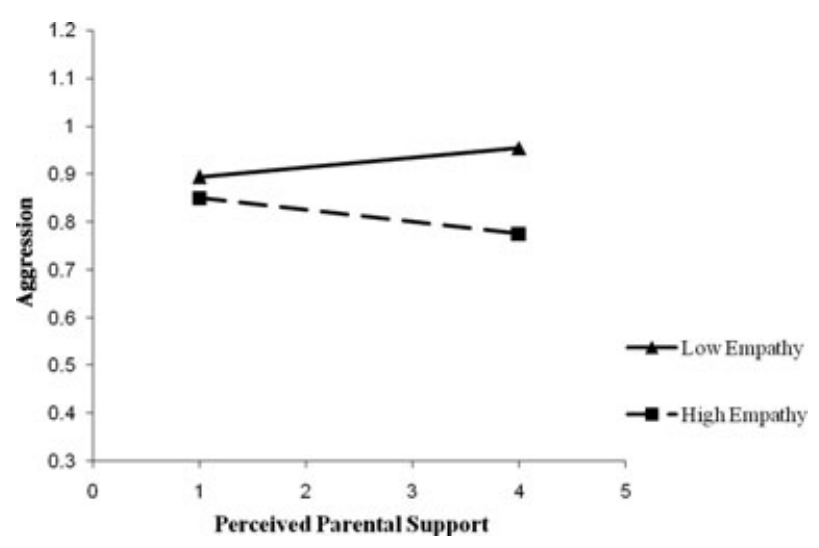

Fig. 1. Interaction of perceived parental support and empathy (at $1 \mathrm{SD}$ and $2 \mathrm{SD}$ above and below mean) in the prediction of aggression (log transformed) at age 15, accounting for the effects of gender and baseline levels of aggression.

to the prediction (see Table III), indicating that the association between perceived parental support and delinquency differs for adolescents with varying levels of empathy. Probing the interaction revealed that the negative association between perceived parental support and delinquent behavior did not reach significance within the range of the empathy scores in our sample (for highest empathy score $P=.09$ ). However, for adolescents with empathy scores lower than 1.13 standard deviations below mean, the positive association between perceived parental support and delinquency was significant $(P<.05$, ranging from $b=.02$ to $b=.04)$. The interactive effect is visualized in Figure 2, showing simple slopes for adolescents with high and low empathy scores (1 SD above and below mean).

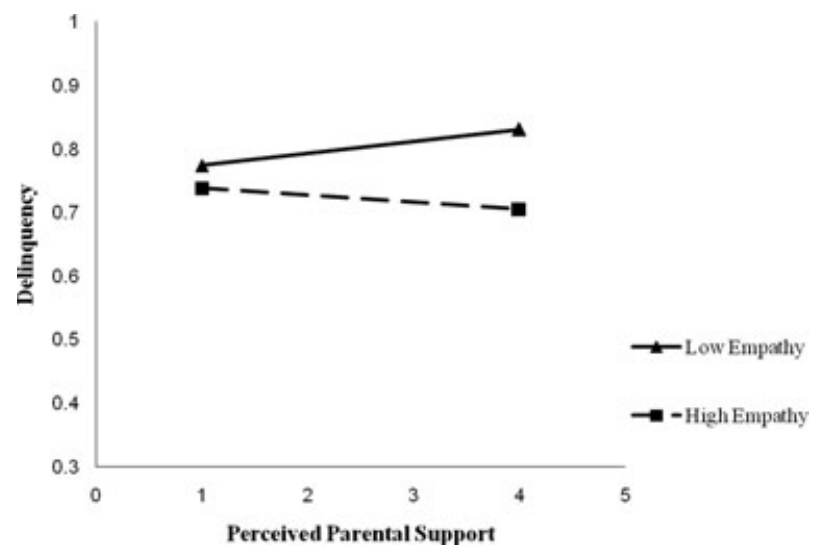

Fig. 2. Interaction of perceived parental support and empathy (at 1 SD and $2 \mathrm{SD}$ above and below mean) in the prediction of delinquency (log transformed) at age 15, accounting for the effects of gender and baseline levels of delinquency.
Thus, the findings of the current study indicate that adolescents' empathic abilities play a moderating role in the association between perceived parental support at age 14 and aggressive and delinquent behavior at age 15. Parental support seems to have more beneficial effects for adolescents high in empathy than for adolescents low in empathy. Whereas highly empathic adolescents who perceive their parents to be supportive show less aggressive behavior one year later, adolescents low in empathy who perceive their parents to be supportive even show more aggressive and delinquent behavior 1 year later.

\section{DISCUSSION}

The aim of the present study was to examine the effects of adolescent empathy and perceived parental support on aggressive and delinquent behavior longitudinally. Convergent with our hypotheses, adolescents' empathy moderated the association between perceived parental support and aggressive and delinquent behavior 1 year later. The associations tended to be negative for adolescents reporting high empathy, but were positive for adolescents reporting low empathy. In contrast, there were no main effects of empathy and of perceived parental support on aggression and delinquency. The results of the current study correspond with theories emphasizing that children vary in their susceptibility to parental support [Belsky, 1997, 2005; Kochanska, 1997].

Consistent with our expectations, empathy interacted with perceived parental support in the prediction of aggression and delinquency. Only for high empathic adolescents, perceived parental support negatively predicted aggression, and marginally significant, negatively predicted delinquency. Thus, adolescents high in empathy gain more from parental support than adolescents low in empathy do, which may be due to a higher sensitivity to positive parental behavior [Blair, 2003]. These results are consistent with the outcomes of studies in clinical samples, in which parental influences were differently related to children's adjustment for children who did or did not lack empathy [Wootton et al., 1997; Oxford et al., 2003]. The current study extended these findings by showing the moderating role of empathy in a community sample of adolescents and in a longitudinal design.

A remarkable result of our study is that low empathic adolescents not only appeared to benefit less from perceived parental support, but moreover, appeared to be detrimentally affected by higher perceived parental support. When low empathic adolescents reported higher perceived support from their 
parents, they even showed higher levels of aggression and delinquency 1 year later. A possible explanation for this finding is that adolescents reporting low empathy have more difficulty with decoding the signals given by their parents than adolescents high in empathy [Davis, 1996; Blair, 2003]. Low empathic adolescents may interpret the support from their parents as acceptance of their misbehavior, and therefore their parents' efforts to offer them warm and supportive care may encourage instead of inhibit them to show aggressive and delinquent behavior. This explanation may be particularly likely when these low empathic adolescents not only perceive their parents to be more supportive, but also experience a lack of control of their parents. This combination characterizes a permissive parenting style.

Although both for aggression and delinquency, the significant interaction effect indicates more positive effects of parental support for adolescents with high empathy scores than for adolescents with low empathy scores, among high empathic adolescents higher support was only significantly related to lower levels of aggression. The negative association between perceived parental support and delinquent behavior 1 year later for adolescents with high empathy scores did not reach significance within the range of scores in our sample. A possible explanation is that delinquency in our assessment mainly involved property offenses, which are not straightforwardly directed toward persons. For instance, stealing goods from a shop or damaging public properties does not directly involve visible harm to a victim, and acts like this may therefore be less consistently influenced by empathy and parental support.

We expected that adolescents' affective empathy would inhibit aggression and delinquency [Davis, 1996; Miller and Eisenberg, 1988] and that adolescents who feel supported by their parents would also be less inclined to show aggressive and delinquent behavior [Branje et al., 2008]. These hypotheses were supported by bivariate concurrent associations in the expected directions, but when we accounted for the effect of gender and for the stability of aggression and delinquency, empathy and perceived parental support at age 14 did not contribute to the prediction of aggression and delinquency 1 year later. However, our result is in line with a transactional view on children's development, which suggests that the interaction between adolescent and environmental characteristics likely explain adolescent development better than do either of these factors on their own [Sameroff and Chandler, 1975].

Our results should be interpreted in light of some limitations. First, we used self-reports to assess em- pathy, parental support, aggression, and delinquency. However, it is not likely that our results are inflated by common method variance, since interaction effects cannot be artificially created [Evans, 1985]. In fact, we found significant interactions despite the influence of common method variance, which offers strong evidence that the interaction effect exists [Siemsen et al., 2010]. Yet, results might have been different when using parents' report of the support they provide, because adolescents' perception of parental support may be influenced by their level of empathy. Second, probing the interaction showed that only for adolescents with fairly high and low empathy scores the associations between perceived parental support and aggression and delinquency are significantly different from zero. This may be due to the characteristics of our sample, consisting of adolescents with relatively high education levels and from two-parent families, which may have reduced the range of empathy scores. However, our hypothesis that adolescents low in empathy are less responsive to parental support was based on findings of studies with clinical samples. The fact that in our relatively well-functioning community-based sample we do find support for the hypothesis that low empathic adolescents benefit less from parental support than do high empathic adolescents, but that the effects are only significant at the lower and higher end of the range of scores in our sample, suggests that it actually is a phenomenon of more diverse populations. Third, as we used only a subscale of the IECA [Bryant, 1982; de Wied et al., 2007], in which responsiveness to another person's sadness is measured, we do not know whether our results will hold for affective empathy in general. Finally, our study is correlational. Therefore, we cannot draw conclusions about causality, and the effects we found of perceived parental support on aggressive and delinquent behavior, could include influences of adolescent behavior on the parent. Experimental designs are needed to examine whether empathy indeed affects adolescents ability to derive benefit from parental support.

Despite the limitations, we believe the present study advances our understanding of the role of empathy and parental support in the development of aggressive and delinquent behavior. By investigating these associations longitudinally in a community sample, we extended research that was done in clinical samples. Empathy indeed appeared to play an important role in the relation between perceived parental support and aggressive and delinquent behavior in adolescence. Although perceived parental support is an important factor in adolescent adjustment, the effects vary for adolescents with different levels of empathy. 
High empathic adolescents show less aggressive behavior when they perceive their parents to be more supportive, whereas low empathic adolescents seem not to derive this benefit and even show more aggressive and delinquent behavior when they perceive their parents to be more supportive.

\section{REFERENCES}

Arım RG, Dahinten VS, Marshall SK, Shapka JD. 2011. An examination of the reciprocal relationships between adolescents' aggressive behaviors and their perceptions of parental nurturance. J Youth Adolesc 40:207-220.

Baerveldt C, Van Rossem R, Vermande M. 2003. Pupils' delinquency and their social networks: A test of some network assumptions of the ability and inability models of delinquency. Neth J Soc Sci 39:107-125.

Bandura A, Caprara GV, Barbaranelli C, Gerbino M, Pastorelli C. 2003. Role of affective self-regulatory efficacy in diverse spheres of psychosocial functioning. Child Dev 74:769-782.

Barnes GM, Hoffman JH, Welte JH, Farrell MP, Dintcheff BA. 2006. Effects of parental monitoring and peer deviance on substance use and delinquency. J Marriage Fam 68:1084-1104.

Batanova MD, Loukas A. 2011. Social anxiety and aggression in early adolescents: Examining the moderating roles of empathic concern and perspective taking. J Youth Adolesc 40:1534-1543.

Bauer DJ, Curran PJ. 2005. Probing interactions in fixed and multilevel regression: Inferential and graphical techniques. Multivar Behav Res 40:373-400.

Belsky J. 1997. Theory testing, effect-size evaluation, and differential susceptibility to rearing influence: The case of mothering and attachment. Child Dev 68:598-600.

Belsky J. 2005. Differential susceptibility to rearing influence: An evolutionary hypothesis and some evidence. In: Ellis BJ, Bjorklund DF, editors. Origins of the social mind: Evolutionary psychology and child development. New York: Guilford. pp 139-163.

Bjorkqvist K, Lagerspetz KMJ, Österman K. 1992. Do girls manipulate and boys fight? Developmental trends in regard to direct and indirect aggression. Aggr Behav 18:117-127.

Blair RJR. 2003. Facial expressions, their communicatory functions and neuro-cognitive substrates. Philos Trans R Soc Lond Ser B 358:561.

Branje SJT, Hale WW III, Frijns T, Meeus WHJ. 2010. Longitudinal associations between perceived parent-child relationship quality and depressive symptoms in adolescence. J Abnorm Child Psychol $38: 1-13$.

Branje SJT, Hale WW III, Meeus WHJ. 2008. Reciprocal development of parent-adolescent support and adolescent problem behaviors. In: Kerr M, Stattin H, Engels RCME, editors. What can parents do? New insights into the role of parents in adolescent problem behavior. Chichester, UK: Wiley. pp 135-162.

Bryant BK. 1982. An index of empathy for children and adolescents. Child Dev 53:413-425.

Caravita SCS, Di Blasio P, Salmivalli C. 2009. Unique and interactive effects of empathy and social status on involvement in bullying. Soc Dev 18:140-163.

Card NA, Stucky BD, Sawalani GM, Little TD. 2008. Direct and indirect aggression during childhood and adolescence: A meta-analytic review of gender differences, intercorrelations, and relations to maladjustment. Child Dev 79:1185-1229.

Carlo G, Raffaelli M, Laible DJ, Meyer KA. 1999. Why are girls less physically aggressive than boys' personality and par- enting mediators of physical aggression. Sex Roles 40:711729.

Carrasco M, Barker ED, Tremblay RE, Vitaro F. 2006. Eysenck's personality dimensions as predictors of male adolescent trajectories of physical aggression, theft and vandalism. Pers Indiv Differ 41:1309-1320.

Caspi A, Moffitt TE. 2006. Gene-environment interactions in psychiatry: Joining forces with neuroscience. Nat Rev Neurosci 7:583-590.

Cohen D, Strayer J. 1996. Empathy in conduct-disordered and comparison youth. Dev Psychopathol 32:988-998.

Davis MH. 1996. Empathy: A social psychological approach. Boulder: Westview Press.

Davis MH, Franzoi SL. 1991. Stability and change in adolescent selfconsciousness and empathy. J Res Pers 25:70-87.

De Kemp RAT, Overbeek GJ, De Wied M, Engels RCME, Scholte RHJ. 2007. Early adolescent empathy, parental support, and antisocial behavior. J Genet Psychol 168:5-18.

De Wied M, Maas C, van Goozen S, Vermande M, Engels R, Meeus W, et al. 2007. Bryant's empathy index: A closer examination of its internal structure. Eur J Psychol Assess 23:99-104.

Deković M, Janssens JMAM, As N. 2003. Family predictors of antisocial behavior in adolescence. Family Process 42:223-235.

Edens JF, Skopp NA, Cahill MA. 2008. Psychopathic features moderate the relationship between harsh and inconsistent parental discipline and adolescent antisocial behavior. J Clin Child Adoles Psychol 37:472-476.

Eisenberg N. 2000. Emotion, regulation, and moral development. Annu Rev Psychol 51:665-697.

Eisenberg N, Lennon R. 1983. Sex differences in empathy and related capacities. Psychol Bull 94:100-131.

Endresen IM, Olweus D. 2001. Self-reported empathy in Norwegian adolescents: Sex differences, age trends, and relationship to bullying. In: Bohart AC, Stipek DJ, editors. Constructive and destructive behavior: Implications for family, school and society. Washington, DC: American Psychological Association. pp 147-166.

Essex MJ, Armstrong JM, Burk LR, Goldsmith HH, Boyce WT. 2011. Biological sensitivity to context moderates the effects of the early teacher-child relationship on the development of mental health by adolescence. Dev Psychopathol 23:149-161

Estévez E, Herrero J, Martínez B, Musitu G. 2006. Aggressive and nonaggressive rejected students: An analysis of their differences. Psychol Schools 43:387-400.

Evans MG. 1985. A Monte Carlo study of the effects of correlated method variance in moderated multiple regression analysis. Organ Behav Hum Dec 36:305-323.

Feshbach ND, Feshbach S. 2009. Empathy and education. In: Decety J, Ickes WJ, editors. The social neuroscience of empathy. Cambridge: The MIT Press. pp 85-98.

Furman W, Buhrmester D. 1985. Children's perceptions of the personal relationships in their social networks. Dev Psychol 21:1016.

Furman W, Buhrmester D. 1992. Age and sex differences in perceptions of networks of personal relationships. Child Dev 63:103-115.

Hayes AF, Matthes J. 2009. Computational procedures for probing interactions in OLS and logistic regression: SPSS and SAS implementations. Behav Res Methods 41:924-936.

Helsen M, Vollebergh W, Meeus WHJ. 2000. Social support from parents and friends and emotional problems in adolescence. J Youth Adolesc 29:319-335.

Hoeve M, Dubas JS, Eichelsheim VI, Van Der Laan PH, Smeenk W, Gerris JRM. 2009. The relationship between parenting and delinquency: A meta-analysis. J Abnorm Child Psychol 37:749775 .

Hoffman ML. 2001. Empathy and moral development: Implications for caring and justice. New York: Cambridge University Press. 
Hyde LW, Shaw DS, Moilanen KL. 2010. Developmental precursors of moral disengagement and the role of moral disengagement in the development of antisocial behavior. J Abnorm Child Psychol 38:197-209.

Jolliffe D, Farrington DP. 2004. Empathy and offending: A systematic review and meta-analysis. Aggr Violent Behav 9:441-476.

Jolliffe D, Farrington DP. 2011. Is low empathy related to bullying after controlling for individual and social background variables? J Adolesc 34:59-71.

Kaukiainen A, Bjorkqvist K, Lagerspetz K, Osterman K, Salmivalli C, Rothberg S, et al. 1999. The relationships between social intelligence, empathy, and three types of aggression. Aggr Behav 25:81-89.

Klein Velderman M, Bakermans-Kranenburg MJ, Juffer F, van IJzendoorn, MH. 2006. Effects of attachment-based interventions on maternal sensitivity and infant attachment: Differential susceptibility of highly reactive infants. J Fam Psychol 20:266.

Kochanska G. 1997. Multiple pathways to conscience for children with difficult temperaments: From toddlerhood to age 5. Dev Psychol 33:228-240.

Lahey BB, Waldman ID, McBurnett, K. 1999. Annotation: The development of antisocial behavior: An integrative causal model. J Child Psychol Psychiatry 40:669-682.

Loudin JL, Loukas A, Robinson S. 2003. Relational aggression in college students: Examining the roles of social anxiety and empathy. Aggr Behav 29:430-439.

Meeus W, Branje S, Overbeek GJ. 2004. Parents and partners in crime: A six-year longitudinal study on changes in supportive relationships and delinquency in adolescence and young adulthood. J Child Psychol Psychiatry 45:1288-1298.

Miller PA, Eisenberg N. 1988. The relation of empathy to aggressive and externalizing/antisocial behavior. Psychol Bull 103:324-344.

Moffitt TE, Caspi A. 2001. Childhood predictors differentiate lifecourse persistent and adolescence-limited pathways, among males and females. Dev Psychopathol 13:355-375.

Olweus D, Endresen IM. 1998. The importance of sex-of stimulus object: Age trends and sex differences in empathic responsiveness. Soc Dev 7:370-388.
Oxford M, Cavell TA, Hughes JN. 2003. Callous/unemotional traits moderate the relation between ineffective parenting and child externalizing problems: A partial replication and extension. J Clin Child Adolesc Psychol 32:577-585.

Robinson R, Roberts WL, Strayer J, Koopman R. 2007. Empathy and emotional responsiveness in delinquent and non-delinquent adolescents. Soc Dev 16:555-579.

Sameroff AJ, Chandler MJ. 1975. Reproductive risk and the continuum of caretaking casualty. In: Horowitz FD, Hetherington M, Scarr-Salapatek S, Siegel G, editors. Review of child development research. vol. 4. Chicago: University of Chicago Press. pp 187244.

Schaffer M, Clark S, Jeglic EL. 2009. The role of empathy and parenting style in the development of antisocial behaviors. Crime Delinq 55:586-599.

Shechtman Z. 2002. Cognitive and affective empathy in aggressive boys: Implications for counseling. Int J Adv Couns 24:211-222.

Siemsen E, Roth A, Oliveira P. 2010. Common method bias in regression models with linear, quadratic, and interaction effects. Organ Res Methods 13:456.

Simons RL, Johnson C, Conger RD. 1994. Harsh corporal punishment versus quality of parental involvement as an explanation of adolescent maladjustment. J Marriage Fam 56:591607.

Van der Laan AM, Blom M. 2011. Zelfgerapporteerde daders [Self reported offenders]. In: van der Laan AM, Blom M, editors. Ontwikkelingen in zelfgerapporteerde daders, door de politie aangehouden verdachten en strafrechtelijke daders op basis van de monitor jeugdcriminaliteit 2010. Den Haag, The Netherlands: WODC.

Van Doorn MD, Branje SJT, Meeus WHJ. 2011. Developmental changes in conflict resolution styles in parent-adolescent relationships: A four-wave longitudinal study. J Youth Adolesc 40:97-107.

Windle M. 1992. Temperament and social support in adolescence: Interrelations with depressive symptoms and delinquent behaviors. J Youth Adolesc 21:1-21.

Wootton JM, Frick PJ, Shelton KK, Silverthorn P. 1997. Ineffective parenting and childhood conduct problems: The moderating role of callous-unemotional traits. J Consult Clin Psychol 65:301-308. 